\title{
Selective Electroless Silver Deposition on Graphene Edges
}

Durhuus, D.; Larsen, M. V.; Andryieuski, Andrei; Malureanu, Radu; Pizzocchero, Filippo; Bøggild, Peter; Lavrinenko, Andrei

Published in:

Journal of the Electrochemical Society

Link to article, DOI:

10.1149/2.0571506jes]

Publication date:

2015

Document Version

Publisher's PDF, also known as Version of record

Link back to DTU Orbit

Citation (APA):

Durhuus, D., Larsen, M. V., Andryieuski, A., Malureanu, R., Pizzocchero, F., Bøggild, P., \& Lavrinenko, A. (2015). Selective Electroless Silver Deposition on Graphene Edges. Journal of the Electrochemical Society, 162(6), D213-217. https://doi.org/10.1149/2.0571506jes]

\section{General rights}

Copyright and moral rights for the publications made accessible in the public portal are retained by the authors and/or other copyright owners and it is a condition of accessing publications that users recognise and abide by the legal requirements associated with these rights.

- Users may download and print one copy of any publication from the public portal for the purpose of private study or research.

- You may not further distribute the material or use it for any profit-making activity or commercial gain

- You may freely distribute the URL identifying the publication in the public portal

If you believe that this document breaches copyright please contact us providing details, and we will remove access to the work immediately and investigate your claim. 


\title{
Selective Electroless Silver Deposition on Graphene Edges
}

\author{
D. Durhuus, ${ }^{\text {a }}$ M. V. Larsen, ${ }^{\text {a }}$ A. Andryieuski, ${ }^{\mathrm{a}, \mathrm{z}}$ R. Malureanu, ${ }^{\mathrm{a}}$ F. Pizzocchero, ${ }^{\mathrm{b}}$ P. Bøggild,, $\mathrm{c}$ \\ and A. V. Lavrinenko ${ }^{a}$
}

${ }^{a}$ DTU Fotonik, Technical University of Denmark, Kongens Lyngby 2800, Denmark

${ }^{b}$ DTU Nanotech, Technical University of Denmark, Kongens Lyngby 2800, Denmark

${ }^{c}$ Center for Nanostructured Graphene (CNG), Technical University of Denmark, Kongens Lyngby 2800, Denmark

\begin{abstract}
We demonstrate a method of electroless selective silver deposition on graphene edges or between graphene islands without covering the surface of graphene. Modifications of the deposition recipe allow for decoration of graphene edges with silver nanoparticles or filling holes in damaged graphene on silica substrate and thus potentially restoring electric connectivity with minimal influence on the overall graphene electrical and optical properties. The presented technique could find applications in graphene based transparent conductors as well as selective edge functionalization and can be extended to other metals than silver.

(C) The Author(s) 2015. Published by ECS. This is an open access article distributed under the terms of the Creative Commons Attribution 4.0 License (CC BY, http://creativecommons.org/licenses/by/4.0/), which permits unrestricted reuse of the work in any medium, provided the original work is properly cited. [DOI: 10.1149/2.0571506jes] All rights reserved.
\end{abstract}

Manuscript submitted December 8, 2014; revised manuscript received February 4, 2015. Published March 10, 2015.

Graphene is a material with unprecedented physical properties, ${ }^{1,2}$ and the understanding of these properties has tremendously improved in recent years. Graphene is highly flexible, mechanically very strong material with a charge carrier mobility ${ }^{3}$ higher than $200000 \mathrm{~cm}^{2} / \mathrm{V} \cdot \mathrm{s}$ and an electrical conductivity twice that of copper. For electronic and infrared photonic applications a great advantage of graphene is its linear dispersion relation and tunable conductivity. At the same time a single sheet of graphene absorbs $2.3 \%$ of visible light intensity, ${ }^{4}$ which is considerable taking into account its single atomic layer thickness, but small compared to other conducting films, which are invariably thicker. These properties contribute to making graphene suitable for optoelectronic and photovoltaic applications requiring transparent electrodes such as light-emitting diodes, solar cells and touchscreens ${ }^{5}$ thus replacing scarce, brittle and relatively expensive indium tin oxide that is extensively used nowadays. Moreover, largearea graphene and graphene-based materials are promising for nonlinear optical applications, ${ }^{6}$ sensing $^{7}$ and catalysis. ${ }^{8}$

Various methods for graphene production exist ${ }^{9}$ : liquid exfoliation, reduction from graphene oxide (high throughput but low-quality), mechanical exfoliation (high-quality in small areas), thermal decomposition of silicon carbide (high quality, large-area and expensive), or chemical vapor deposition (CVD) (medium-high quality). For the CVD processes, graphene is generally grown on copper ${ }^{10}$ and then transferred to an insulating substrate. ${ }^{11}$ During transfer various microand macro- damages such as cracks and holes are commonly introduced in the graphene, breaking electrical connections within the graphene film and thus impairing the overall electrical properties. ${ }^{12}$

To repair these defects and thus to recover the combination of high optical and electrical quality of the film it was suggested to connect graphene islands or graphene oxide flakes with percolated carbon nanotubes ${ }^{13}$ or silver nanowires. ${ }^{13-20}$ Such conductive films have been applied as electrodes in stretchable light-emitting diodes, ${ }^{16}$ ultraviolet light-emitting diodes, ${ }^{18}$ and for detection of hydrogen peroxide. ${ }^{20}$ The randomly placed nanowires form a percolating network, so the resulting composite material is transparent and conductive, but not tunable anymore, as variation of the electrochemical potential of graphene does not influence the conductivity of the silver nanowires.

Another research direction in graphene-metal composites is to combine graphene with metal nanoparticles. ${ }^{8,21}$ The nanoparticles can in principle be drop-casted or formed with electron beam evaporation under the metal percolation limit, ${ }^{22}$ but a more efficient and versatile method is to directly grow the nanoparticles on graphene or graphene oxide, either electrochemically as shown on graphite ${ }^{23}$ or with electroless method. ${ }^{24-34}$ Such composites can be used for catalysis, ${ }^{29,31-33}$ Li-ion batteries, ${ }^{35}$ surface-enhanced Raman spectroscopy templates, ${ }^{30}$ chemical sensing, ${ }^{26}$ biological disinfection ${ }^{28,36}$ and even nonlinear optics. ${ }^{37}$ In these cases, graphene or graphene oxide are used mostly as a supporting template for the nanoparticles, rather than a conductive film. Electroless deposition in general takes place on the whole surface of the graphene flake, covering it with either isolated nanoparticles or a continuous metal film. There are, however, applications of the metal nanoparticles where full coverage should be avoided, leaving nanoparticles positioned only at the edge of graphene or in selected areas where they perform their function. For example, it has been demonstrated that silver nanoparticles on graphene under annealing and E-beam irradiation in oxygen atmosphere can produce crystallographically oriented long nanopatterned channels and possibly allowing for near-deterministic graphene nanopattering, ${ }^{38,39}$ and here the particles should ideally be aligned along the edges where the channel formation commences. A more pragmatic reason is the cost of the deposited material; limiting the deposition to the edges will obviously lead to a far smaller consumption of metal. In general, selectivity of deposition is always considered as a strong technological advance.

In this work we demonstrate an electroless method to deposit silver nanoparticles selectively at or between graphene edges, with varied degree of coverage. Nanoparticles can fix broken electrical connections between the graphene islands virtually without destroying the electrochemical potential tunability of graphene. Moreover, a nanoparticle can act as the nucleation point for silver nanowire growth. The advantage of using electroless deposition is its relatively low cost and easy scalability toward mass production. The electroless silver deposition process used here is based on the silver mirror reaction developed initially for deposition on polymer structures. ${ }^{40,41}$ In this work we modify the procedure to achieve selective deposition on the edge of graphene flakes and on $\mathrm{SiO}_{2}$ substrate.

\section{Methods}

Graphene fabrication and transfer-Graphene is grown in the Aixtron Black Magic vertical CVD system with a recipe similar to the previously reported ones. ${ }^{12,42,43}$ We use commercial copper foil (Alpha Aesar $99.9999 \% \mathrm{Cu}$ ) as catalysts for graphene growth. Before the growth the foils are annealed at $1050^{\circ} \mathrm{C}$ in $\mathrm{Ar} / \mathrm{H}_{2}$ atmosphere. The growth occurs at the same temperature for 10-30 minutes after the addition of $\mathrm{CH}_{4}$ flow in the chamber. The varying growth time results in different coverages of graphene on copper. All graphene growths were investigated by Raman spectroscopy, confirming single- or fewlayer graphene with $\mathrm{I}(\mathrm{D}) / \mathrm{I}(\mathrm{G})$ ratio of order $0.1-0.2$.

The transfer is done by etching the copper foil with ammonium persulfate, with the graphene supported by a poly(methyl metacrylate) (PMMA) layer. The adhesion of the graphene/PMMA onto an oxidized $\mathrm{Si}$ surface $\left(100 \mathrm{~nm}\right.$ of $\left.\mathrm{SiO}_{2}\right)$ is promoted by baking at $180^{\circ} \mathrm{C}$. The target substrate is pre-treated in oxygen plasma to promote graphene adhesion. Finally, the PMMA is removed in acetone. 
Table I. Solutions used for electroless silver deposition.

Acidic tin(II)chloride solution

$500 \mu \mathrm{L}\left(15 \% \mathrm{SnCl}_{2} ; 7.5 \% \mathrm{HCl} ; 22 \% \mathrm{CH}_{3} \mathrm{COOH}\right)$

$$
25.0 \mathrm{ml} \mathrm{H}_{2} \mathrm{O}
$$

Standard electroless silver deposition.- (i) Silver is deposited onto graphene on $\mathrm{SiO}_{2}$ samples, through reduction of aqueous silver nitrate solution with formaldehyde. The chemical compounds used are listed in Table I (all reagents from Sigma-Aldrich ${ }^{44}$ ). We used deionized millipore (MilliQ) filtered water at all steps. The important reaction steps in the silver deposition process are as follows: The sample is placed in the acidic tin(II)chloride solution for 5 minutes at room temperature. The acidic tin(II)chloride solution is used for surface treatment of the sample. This process binds $\mathrm{Sn}^{2+}$-ions to the surface (to hydroxyl groups on the surface) as illustrated in Fig. 1a. These particles act as seeds from which the silver crystals grow. The sample is then rinsed for 15 minutes with deionized water to remove excess $\mathrm{SnCl}_{2}$ solution.

(ii) Afterwards the sample is immersed for 1 minute in ammoniacal silver nitrate solution that is prepared with the following reaction:

$$
2 \mathrm{AgNO}_{3}{ }^{(\mathrm{aq})}+2 \mathrm{NH}_{4} \mathrm{OH}^{(\mathrm{aq})} \rightarrow \mathrm{Ag}_{2} \mathrm{O}^{(\mathrm{s})}+2 \mathrm{NH}_{4} \mathrm{NO}_{3}{ }^{(\mathrm{aq})}+\mathrm{H}_{2} \mathrm{O},
$$

resulting in a cloudy solution. Adding more ammonium hydroxide shifts the equilibrium, creating silver ammonium nitrate,

$$
\begin{gathered}
\mathrm{Ag}_{2} \mathrm{O}^{(\mathrm{s})}+2 \mathrm{NH}_{3}{ }^{(\mathrm{aq})}+2 \mathrm{NH}_{4} \mathrm{NO}_{3}{ }^{(\mathrm{aq})}+\mathrm{H}_{2} \mathrm{O} \\
\rightarrow 2 \mathrm{Ag}\left(\mathrm{NH}_{3}\right)_{2} \mathrm{NO}_{3}{ }^{(\mathrm{aq})}+2 \mathrm{NH}_{4} \mathrm{OH}^{(\mathrm{aq})},
\end{gathered}
$$

which exists as ions in the solution:

$$
\begin{aligned}
& \mathrm{Ag}\left(\mathrm{NH}_{3}\right)_{2} \mathrm{NO}_{3}{ }^{(\mathrm{aq})}+\mathrm{NH}_{4} \mathrm{OH}^{(\mathrm{aq})} \\
& \quad \rightarrow \mathrm{Ag}\left(\mathrm{NH}_{3}\right)_{2}{ }^{+}+\mathrm{NO}_{3}{ }^{-}+\mathrm{NH}_{4}{ }^{+}+\mathrm{OH} .
\end{aligned}
$$

When the pretreated sample is immersed into this solution the silver atoms bond to the $\mathrm{Sn}^{2+}$ groups on the surface of the sample. This step is illustrated in Fig. 1b.

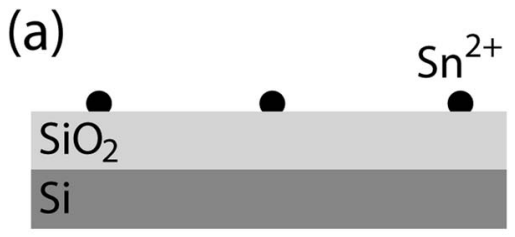

(b)

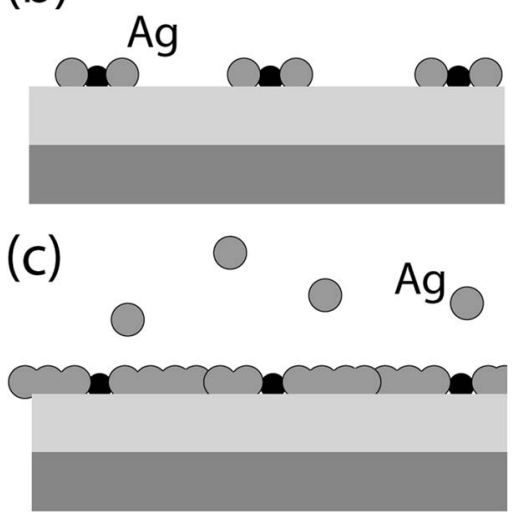

Figure 1. Standard procedure: (a) In the acidic tin(II)chloride solution $\mathrm{Sn}^{2+}$ is bonded to the $\mathrm{SiO}_{2}$ surface for adhesion promotion. (b) In the ammoniacal silver nitrate solution silver atoms bond to $\mathrm{Sn}^{2+}$. (c) After the formaldehyde solution is added the silver nanoparticles grow on the Ag-Sn-seeds.
Ammoniacal silver nitrate solution

Formaldehyde solution

$$
\begin{array}{cc}
1.25 \mathrm{ml}\left(2.0 \% \mathrm{AgNO}_{3}, 5.0 \% \mathrm{NH}_{3}\right) & 250 \mu \mathrm{L} \mathrm{CHOH} \\
57 \mu \mathrm{L} \geq 25 \% \mathrm{NH}_{4} \mathrm{OH} & \\
9.2 \mathrm{ml} \mathrm{H}_{2} \mathrm{O} & 8.0 \mathrm{ml} \mathrm{H}_{2} \mathrm{O}
\end{array}
$$

(iii) Formaldehyde solution is added to the ammoniacal silver nitrate solution containing the sample. After 60 seconds the sample is removed and rinsed with water. Adding the formaldehyde solution to the ammoniacal silver nitrate solution, the silver-ammonia complex is reduced to silver and ammonia:

$$
\begin{aligned}
& \mathrm{HCOH}^{(\mathrm{aq})}+2 \mathrm{OH}^{-}+\mathrm{Ag}\left(\mathrm{NH}_{3}\right)_{2}{ }^{+} \\
& \quad \rightarrow \mathrm{HCOOH}^{(\mathrm{aq})}+\mathrm{H}_{2} \mathrm{O}+2 \mathrm{Ag}^{(\mathrm{s})}+4 \mathrm{NH}_{3}{ }^{(\mathrm{aq})} .
\end{aligned}
$$

Both the ammoniacal silver nitrate and the formaldehyde solutions are cooled down to $5^{\circ} \mathrm{C}$ before the procedure. Silver grows on $\mathrm{Ag}-\mathrm{Sn}$ seeds resulting in a thin layer as illustrated in Fig. 1c.

The standard procedure was initially developed for silver deposition on 3D polymer structures. It is modified here to optimize silver deposition on $\mathrm{SiO}_{2}$ substrates with graphene flakes covering most of the area. The $\mathrm{pH}$ of acidic tin(II)chloride, ammoniacal silver nitrate and final deposition solution was 1,11 and 8, respectively. No damage to graphene was observed after immersion into these solutions. In efforts to achieve deposition with the correct selectivity, the following approach was taken; since tin is used for silver layer adhesion ${ }^{40}$ we excluded tin treatment with the acidic $\mathrm{SnCl}_{2}$ solution to avoid silver on the graphene surface. Furthermore samples were treated with $\mathrm{HCl}$ to eliminate certain functional groups before deposition. Finally the adhesion promoter (tin ions) was deposited on the $\mathrm{SiO}_{2}$ substrate only before the graphene transfer, to avoid silver deposition on the graphene surface.

\section{Results and Discussion}

The samples were characterized using the scanning electron microscope Zeiss Supra VP 40 (SEM). Areas of transferred CVD graphene on $\mathrm{SiO}_{2}$ intentionally contain defects and cracks, as it can be seen from SEM microphotos in Fig. 2a. A Raman spectrum of transferred graphene is shown in the inset of Fig. 2a. Standard electroless silver deposition on these areas produced particles spread all over the surface of the sample, with the highest density (nearly a continuous layer) on graphene (Fig. 2b). A similar procedure applied on graphite has been reported to produce a continuous layer of silver. ${ }^{25}$

As this selectivity is exactly opposite to the requirements stated in the Introduction, several modifications of the procedure were investigated to reverse the selectivity.

Exclusion of tin (II) chloride treatment.. - To avoid deposition of silver on graphene, we excluded the $\mathrm{Sn}^{2+}$ pretreatment of the sample (acidic tin(II)chloride solution). In this way the $\mathrm{Sn}^{2+}$ seeds are not created on silica or on the graphene surface, and thereby the silver growth is hindered. The rest of the process steps remain unchanged except timing. The sample is left in ammoniacal silver nitrate solution for $1 \mathrm{~min}$ and after the addition of formaldehyde another $2 \mathrm{~min}$. In this way we were able to deposit silver exclusively on the $\mathrm{SiO}_{2}$ areas (Fig. 3a). Nevertheless, the silver layer on $\mathrm{SiO}_{2}$ is not continuous, and the deposited silver particles do not appear to bind neither to edges nor to surface of graphene flakes (dark areas in Fig. 3). Increasing the time the sample is left in ammoniacal silver nitrate solution to $3 \mathrm{~min}$ and 4 min after adding formaldehyde has the consequence of starting deposition of the silver particles on graphene (Fig. 3b).

Hydrochloric acid treatment.- Since we found that absence of $\mathrm{Sn}^{2+}$-ions prevents silver deposition on graphene and taking into account that $\mathrm{Sn}^{2+}$ is predominantly attached to OH-groups, ${ }^{25}$ the number of hydroxyl groups was decreased by using concentrated 

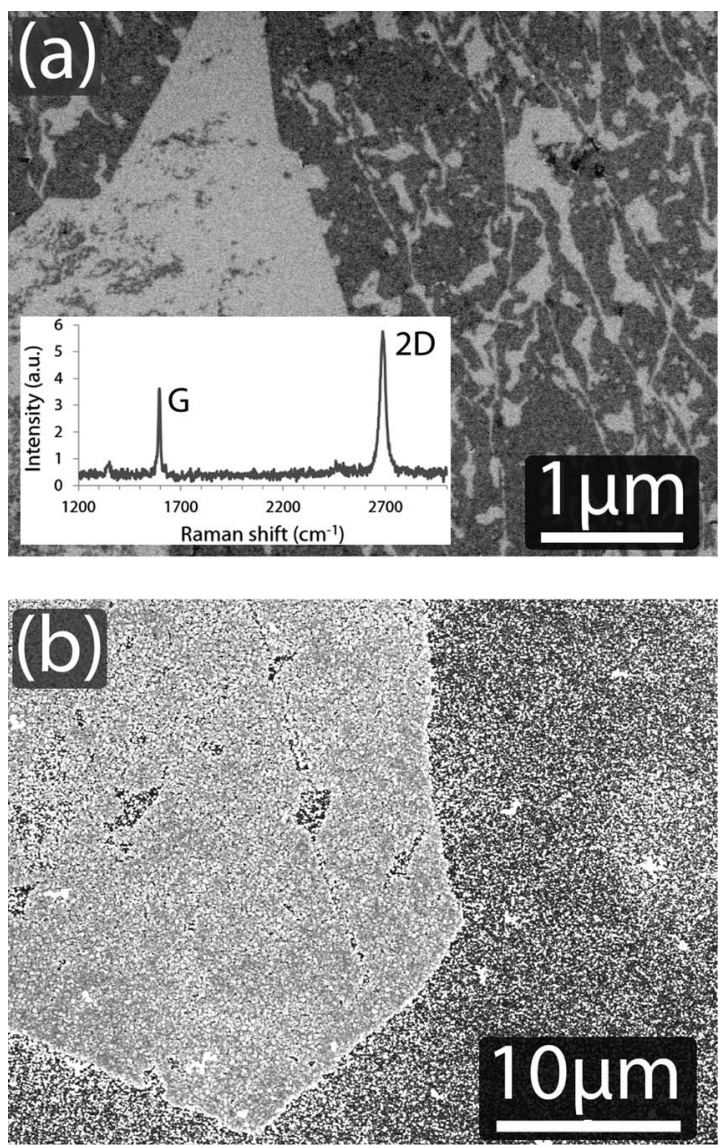

Figure 2. (a) Graphene (dark areas) on $\mathrm{SiO}_{2}$ (bright areas). Damages, such as holes, are seen in graphene. The inset shows Raman spectrum of transferred graphene. (b) When silver is deposited by the standard procedure, the continuous layer of silver on graphene is formed (bright area). There is less silver on the silica substrate (discontinuous layer, dark area).

hydrochloric acid immediately before silver deposition. The binding energy of $\mathrm{OH}$-groups is $0.8-3 \mathrm{eV}^{45}$ and $0.54 \mathrm{eV}^{46}$ respectively for $\mathrm{SiO}_{2}$ and graphene pristine surfaces, while it is larger for defects $(1.8 \mathrm{eV}$ for defected graphene with Stones-Wales and vacancy defects ${ }^{46}$ ).

Therefore, we expect $\mathrm{HCl}$ to remove the majority of $\mathrm{OH}$-groups from the graphene surface and leave silver on $\mathrm{SiO}_{2}$ and along the graphene edges.

We pre-treated the sample with concentrated (37\%) $\mathrm{HCl}$ for $2 \mathrm{~min}$, then rinsed it in DI water and immediately proceeded with the normal electroless silver deposition. This results in higher selectivity of silver toward the graphene edges, as reported in Fig. 4. During deposition the left side of the sample in Fig. 4a is covered by a sample holder, thus no silver is deposited in this area. Nevertheless, to the right from the sample holder edge, the reactants can access the sample surface leading to a complete silver coverage of the sample. In the transition region between these two areas, within approximately $10 \mu \mathrm{m}$ from the continuous silver layer edge, silver grows more actively on the graphene edges. This leads to formation of nanoparticles and even short nanowires, shown in the inset of Fig. 4a. We suggest that this effect can occur due to the reduced concentration of formaldehyde in the area.

We replicated the experiment using a diluted formaldehyde solution $\left(10 \mu \mathrm{L} \mathrm{CHOH}\right.$ and $\left.8.0 \mathrm{ml} \mathrm{H}_{2} \mathrm{O}\right)$. The result, shown in Fig. $4 \mathrm{~b}$, is a higher selectivity of silver to the edges of graphene, not only near the sample holder, but everywhere on the sample. The size of the particles was $70 \pm 19 \mathrm{~nm}$ and their linear density was 5.2 particles per $\mu \mathrm{m}$ of the edge length. Even though small silver particles are seen to bind to the graphene surface or more likely near defects in the graphene sheet, the majority of the larger particles is formed on the edges leaving far less amount on silica.
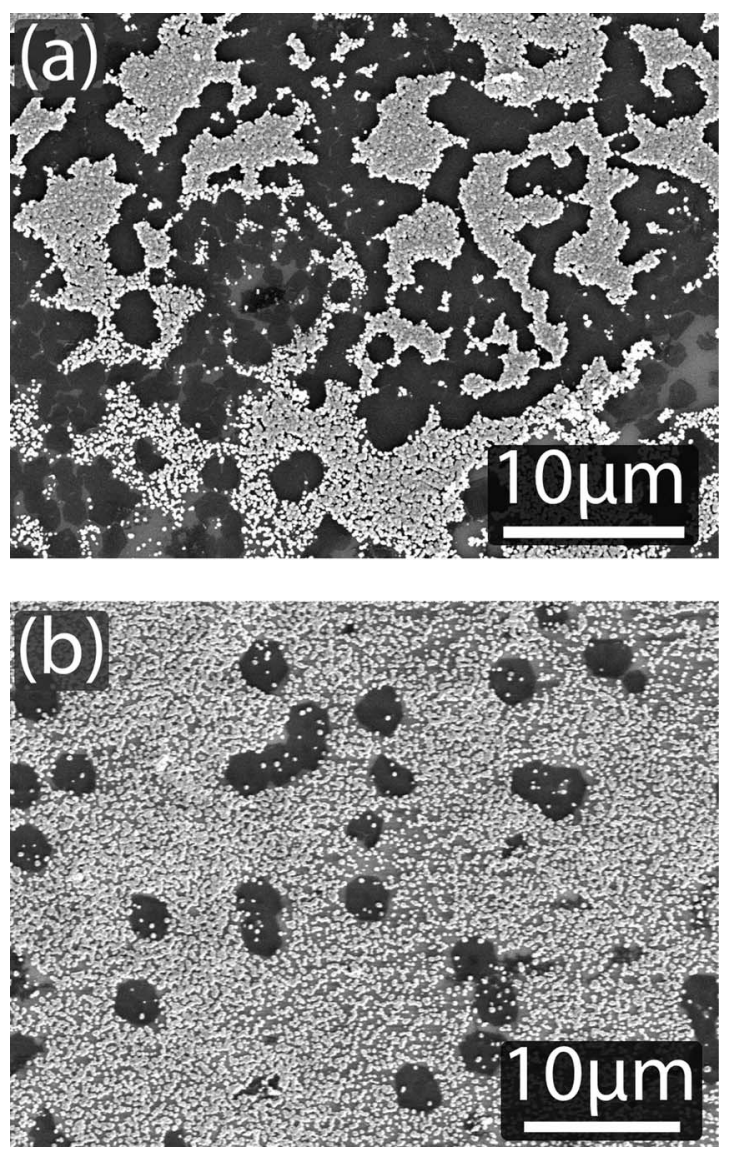

Figure 3. Silver deposited excluding step $1\left(\mathrm{SnCl}_{2}\right.$ treatment $)$ and using different timing in steps 3 and 4 (a) 1 and 2 minutes and (b) 3 and 4 minutes, respectively. The result of excluding step 1 is silver deposition predominantly on silica. The dark areas with no deposited silver are the graphene flakes.

Treating $\mathrm{SiO}_{2}$ with $\mathrm{SnCl}_{2}$ before graphene transfer- The $\mathrm{SiO}_{2}$ substrate was treated with $\mathrm{Sn}^{2+}$ before graphene transfer with the aim of controlling the density of $\mathrm{Sn}^{2+}$ seeds. In particular, our goal was to make sure that no $\mathrm{Sn}^{2+}$-seeds were created on graphene, while depositing a continuous layer of silver on $\mathrm{SiO}_{2}$.

The samples pretreated with $\mathrm{SnCl}_{2}$ and then exposed to oxygen plasma (see Fig. 5a) show smaller density of the silver particles on $\mathrm{SiO}_{2}$ compared to the sample treated with the standard method (Fig. 2b). We can thus conclude that the $\mathrm{Sn}^{2+}$-seed layer is removed by the oxygen plasma treatment. Therefore we performed the transfer without the oxygen plasma treatment of the $\mathrm{SiO}_{2}$ surface. This resulted in silver formation only on the exposed $\mathrm{SiO}_{2}$ areas, yet without forming a continuous layer (Fig. 5b). Moreover, silver deposition is more extensive on no plasma treated silica, as seen comparing Fig. 5a and $5 \mathrm{~b}$. The formation of a continuous layer of silver was obtained by increasing the deposition time to $8 \mathrm{~min}$. In this way, silver forms a nearly continuous layer in most of the $\mathrm{SiO}_{2}$ areas (Fig. 5c). Silver clusters are observed on the graphene surface.

\section{Discussion}

Using the standard electroless formaldehyde-based procedure ${ }^{40}$ of silver deposition, we observe higher density of silver particles on graphene than on the $\mathrm{SiO}_{2}$ substrate (Fig. 2). This undesired selectivity can be explained by larger density of hydroxyl groups on graphene ${ }^{25}$ and consequently that $\mathrm{Sn}^{2+}$ seeds bond to them. Avoiding the $\mathrm{Sn}^{2+}$ pretreatment, the desired selectivity with silver on silica is obtained, however, but not on graphene (Fig. 3). Although the silver layer on silica is discontinuous, even with a longer deposition time, this indicates that the silica surface contains other nucleation points in the 

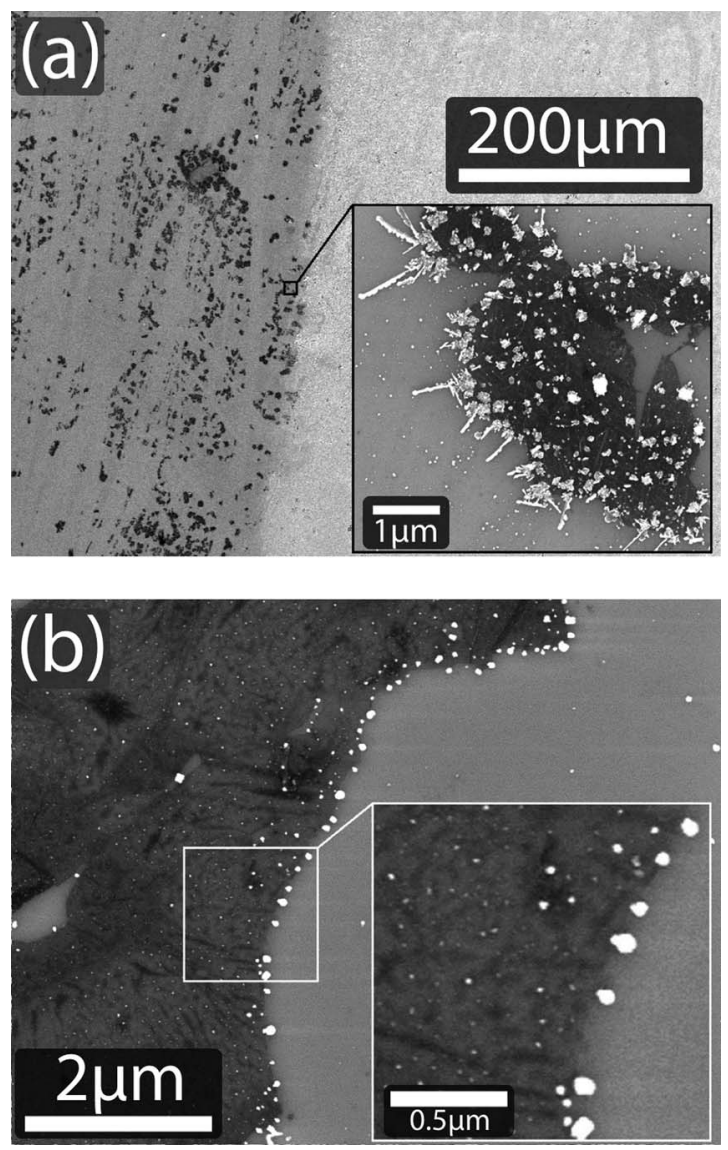

Figure 4. $\mathrm{HCl}$ pretreated samples of graphene followed by silver deposition: Standard procedure with (a) 1 minute in step 4, and (b) 1 minute in step 4 and a lower concentration of solution 2 . Silver has much higher selectivity on the graphene edges.

absence of $\mathrm{SnCl}_{2}$ pre-treatment. In order to fill gaps, cracks and holes in graphene with silver, and to deposit silver exclusively on silica, there are two options: to remove seed points from the graphene surface, but leave them on the edge, or to avoid treating graphene with $\mathrm{SnCl}_{2}$, while treating silica with it before graphene transfer. We have investigated both possibilities and demonstrated silver growth selectively on graphene edges after $\mathrm{HCl}$ treatment (Fig. 4) and continuous silver layer growth on silica, but not on graphene with $\mathrm{SnCl}_{2}$ treatment before the graphene transfer (Fig. 5).

Except graphene edges, preferential silver deposition places can be introduced on graphene surface intentionally by, for example, tuning graphene growth conditions, introducing defects lithographically or drop-casting specific nanoparticles. One aspect not covered in this work, is the possibility and prevalence of silver deposition near vacancy defects inside the graphene, i.e. between edges. In contrast to the edges, the positions of individual vacancies are difficult to assess, which makes such a study significantly more challenging, as there is no simple way to tell if a silver particle located away from an edge was formed there due to a vacancy or other type of structural defect. A study of metal deposition near line defects in graphene has recently been published, however, the metal particles were deposited with atomic layer deposition. ${ }^{47}$

The possibility of growing silver nanowires from the graphene edges is also demonstrated (inset in Fig. 4a), but these results require further investigation. The growth of silver nanowires between graphene edges would be advantageous with respect to random nanowires drop-casting, since the latter leads to current conductivity mainly through the silver nanowires network, so the resulting composite material loses advantages of graphene's tunability.
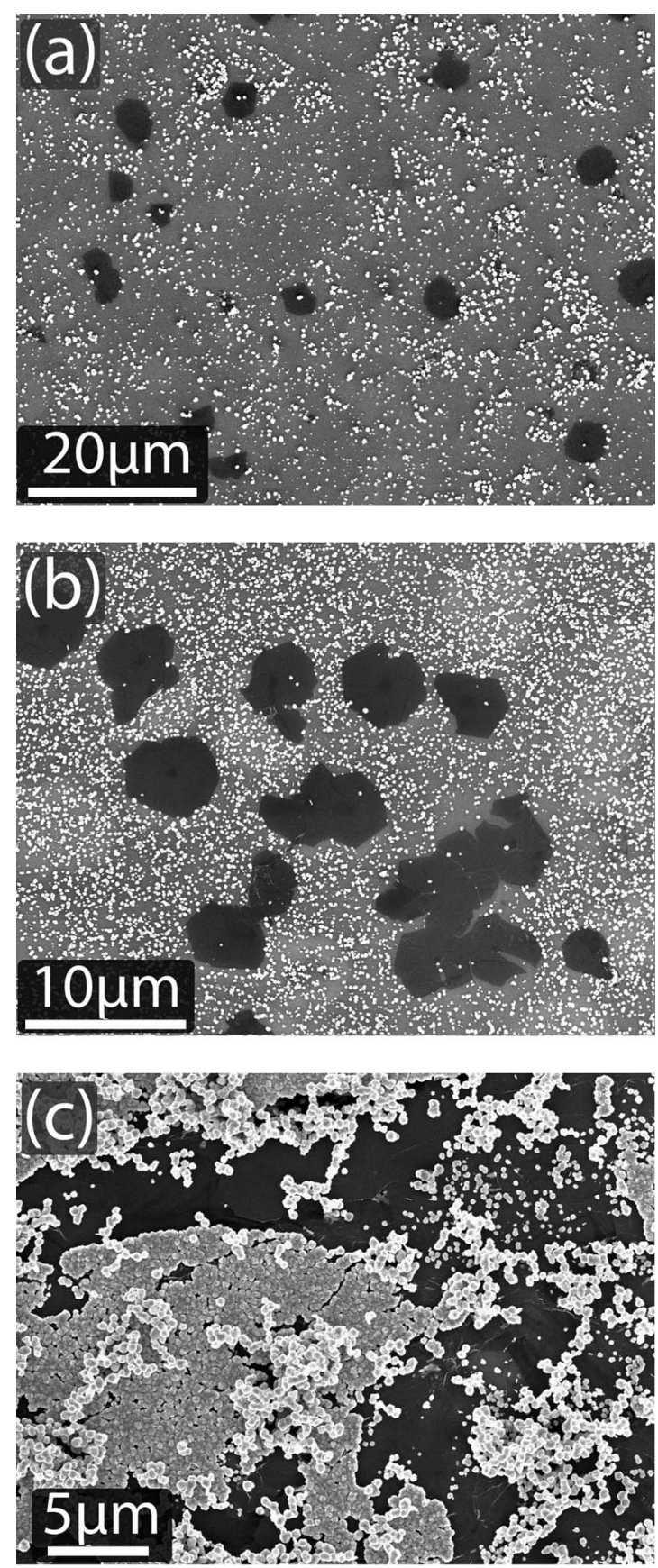

Figure 5. Samples treated with $\mathrm{Sn}^{2+}$ before graphene transfer, followed by step 3 and 4 after the transfer. (a) Transfer after oxygen plasma treatment. (b) and (c) Transfer without use of oxygen plasma. In (a) and (b) silver is deposited by the standard procedure with graphene transferred between step 2 and 3. (c) The same procedure as in (a) and (b), but with 8 minutes in step 4 .

When pretreating the $\mathrm{SiO}_{2}$ substrate with $\mathrm{Sn}^{2+}$ before the graphene transfer, we observed that graphene is surprisingly well transferred without use of oxygen plasma for adhesion promotion. This effect can be due to the $\mathrm{OH}$ groups on graphene interacting with the $\mathrm{Sn}^{2+}$ particles on $\mathrm{SiO}_{2}$.

\section{Conclusions}

In conclusion, we have demonstrated electroless silver nanoparticle decoration of graphene edges. We have also shown selective silver deposition on the $\mathrm{SiO}_{2}$ substrate between but not on top of graphene 
flakes. The nanoparticle decoration can be useful for repairing broken electrical connections in defected graphene for transparent conductive coatings or deterministic graphene nanopatterning, as well as for catalysis, disinfection, sensing, and nonlinear optical applications. The advantage of the electroless method is its scalability for mass production, cost efficiency, no need of high vacuum or a conductive substrate, contrary to the electrodeposition. Thus, the suggested method can be applied to silver deposition on graphene on virtually any substrate (for example, on polymer) and can be employed for effective graphene processing and development of the graphene-based devices. Moreover, the edge selective electroless deposition can be extended to other metals and, potentially, to other two-dimensional materials.

\section{Acknowledgments}

The authors acknowledge Mikkel Dysseholm Mar for SEM training and Tim Booth for useful discussion. A.A. acknowledges financial support from the Danish Council for Independent Research via the GraTer project (Contract No. 0602-02135B). PB and FP acknowledge financial support from EC Graphene FET Flagship (604391), and the Center for Nanostructured Graphene funded by the Danish National Research Foundation (CNG, DNRF58). D.D. and M.V.L. contributed equally to this article.

\section{References}

1. A. K. Geim and K. S. Novoselov, Nat. Mater, 6, 183 (2007).

2. E. Y. Andrei, G. Li, and X. Du, Reports Prog. Phys., 75, 056501 (2012).

3. K. Bolotin et al., Solid State Commun., 146, 351 (2008).

4. R. R. Nair et al., Science (80-.)., 320, 1308 (2008).

5. A. C. Ferrari et al., Nanoscale (2014).

6. F. Bonaccorso, Z. Sun, T. Hasan, and A. C. Ferrari, Nat. Photonics, 4, 611 (2010)

7. W. Yuan and G. Shi, J. Mater. Chem. A, 1, 10078 (2013).

8. B. F. Machado and P. Serp, Catal. Sci. Technol., 2, 54 (2012).

9. K. S. Novoselov et al., Nature, 490, 192 (2012).

10. X. Li et al., Science (80-.)., 324, 1312 (2009).

11. J. Kang, D. Shin, S. Bae, and B. H. Hong, Nanoscale, 4, 5527 (2012).
12. J. D. Buron et al., Nano Lett., 12, 5074 (2012) http://www.ncbi.nlm.nih.gov/ pubmed/22947167.

13. C. Jeong, P. Nair, M. Khan, M. Lundstrom, and M. A. Alam, Nano Lett., 11, 5020 (2011).

14. I. N. Kholmanov et al., Nano Lett., 12, 5679 (2012).

15. D. Lee et al., Nanoscale, 5, 7750 (2013).

16. J. Liang et al., ACS Nano, 8, 1590 (2014).

17. S. Xu et al., CrystEngComm, 16, 3532 (2014).

18. T. Hoon Seo et al., Appl. Phys. Lett., 103, 051105 (2013).

19. K. Naito, N. Yoshinaga, E. Tsutsumi, and Y. Akasaka, Synth. Met., 175, 42 (2013).

20. M. Zhang and Z. Wang, Appl. Phys. Lett., 102, 213104 (2013).

21. C. Xu, X. Wang, and J. Zhu, J. Phys. Chem. C, 112, 19841 (2008),

22. A. M. Zaniewski, M. Schriver, J. Gloria Lee, M. F. Crommie, and A. Zettl, Appl. Phys. Lett., 102, 023108 (2013)

23. R. Penner, J. Phys. Chem. B, 106, 3339 (2002)

24. X.-W. Liu, J.-J. Mao, P.-D. Liu, and X.-W. Wei, Carbon N. Y., 49, 477 (2011)

25. W. Sun, G. Chen, and L. Zheng, Scr. Mater., 59, 1031 (2008).

26. A. Gutés et al., Nanoscale, 4, 438 (2012).

27. W. Lin, X. Xi, and C. Yu, Synth. Met., 159, 619 (2009).

28. M. R. Das et al., Colloids Surf. B. Biointerfaces, 83, 16 (2011).

29. E. K. Jeon et al., Chem. Commun., 49, 3392 (2013).

30. C. Xu and X. Wang, Small, 5, 2212 (2009).

31. K. Han et al., Appl. Phys. Lett., 104, 053101 (2014)

32. T. V. Thu, P. J. Ko, N. H. H. Phuc, and A. Sandhu, J. Nanoparticle Res., 15, 1975 (2013).

33. N. Salam et al., RSC Adv., 4, 10001 (2014).

34. X.-Z. Tang, Z. Cao, H.-B. Zhang, J. Liu, and Z.-Z. Yu, Chem. Commun. (Camb)., 47, 3084 (2011).

35. C. Hsieh, C. Lin, Y. Chen, J. Lin, and H. Teng, Carbon N. Y., 62, 109 (2013).

36. J. Ma, J. Zhang, Z. Xiong, Y. Yong, and X. S. Zhao, J. Mater. Chem., 21, 3350 (2011).

37. Z. Sun et al., Carbon N. Y., 62, 182 (2013)

38. F. Pizzocchero et al., J. Phys. Chem. C, 118, 4297 (2014).

39. T. J. Booth et al., Nano Lett., 11, 2689 (2011).

40. R. Malureanu, M. Zalkovskij, A. Andryieuski, and A. V. Lavrinenko, J. Electrochem. Soc., 157, K284 (2010).

41. R. Malureanu et al., Appl. Phys. A, 103, 749 (2010).

42. J. Buron et al., Nano Lett., 14, 6348 (2014).

43. F. Pizzocchero et al., Carbon N. Y., 85, 397 (2015).

44. SigmaAldrichCo www.sigmaaldrich.com, last accessed: March 2015.

45. S. Iarlori, D. Ceresoli, M. Bernasconi, D. Donadio, and M. Parrinello, J. Phys. Chem $B, \mathbf{1 0 5}, 8007$ (2001).

46. N. Ghaderi and M. Peressi, J. Phys. Chem. C, 114, 21625 (2010)

47. K. Kim et al., Nat. Commun., 5, 4781 (2014). 